\title{
Compreendendo critérios de validação de problemas de contagem utilizados por professores da Educação Básica
}

\author{
Luzia da Costa Tonon Martarelli ${ }^{1}$ \\ Ulisses Dias da Silva ${ }^{2}$
}

\begin{abstract}
RESUMO
Esse artigo analisa as concepções e crenças de professores sobre a validade de diferentes soluções de um problema de contagem. Essa pesquisa se justifica pois: (i) problemas de contagem podem apresentar uma série de soluções que envolvem diferentes formas de pensar; (ii) professores costumam valorizar soluções com base em raciocínios padronizados, muitas vezes considerando inválidas soluções corretas porque não se enquadram nesses modelos e (iii) compreender as concepções e crenças desses professores pode servir para estabelecer estratégias, tanto na formação inicial, quanto continuada, para reconhecer e valorizar raciocínios não-padronizados. Foram realizadas entrevistas semiestruturadas com quatro sujeitos pré-selecionados, que foram analisadas segundo a Análise de Conteúdo, e após sucessivas categorizações, foram identificadas três posturas acerca do ensino de contagem, oriundas das entrevistas: postura sintetizante, dialógica e contraditória. Concluímos que diferentes posturas sobre as validações de soluções se expressam em concepções de ensino de contagem em sala de aula, com implicações para qual forma de ensinar e avaliar matemática será apresentada aos alunos.
\end{abstract}

PALAVRAS-CHAVE: Formação de Professores. Contagem. Concepções e Crenças. Análise de Soluções de Problemas.

\footnotetext{
${ }^{1}$ Doutora em Estatística. Universidade Federal do Estado do Rio de Janeiro, Rio de Janeiro, Rio de Janeiro, Brasil. https://orcid.org/0000-0002-3311-5408.luzia.tonon@uniriotec.br.

${ }^{2}$ Doutor em Ensino de Matemática. Universidade Federal do Rio de Janeiro, Rio de Janeiro, Rio de Janeiro, Brasil. https://orcid.org/0000-0003-3919-2786.ulissesdias@ufrj.br.
} 
Understanding Basic Education Teacher's Validation Criteria for Combinatory Problems

\begin{abstract}
This article analyses teachers' beliefs about validation of different solutions of a combinatory problem. Justifications of this research includes: (i) combinatory problems can have multiple solutions, with different ways of thinking; (ii) teachers valorize standardized solutions, many times invalidating right answers not compatible with these standards and (iii) understanding teachers' beliefs and conceptions can help to stablish formation strategies to recognize and valorize to nonstandardized thinking. There were made four semi structured interviews with four pre-selected participants. Interviews were analyzed with Content Analysis method and, by successive categorization, three instances about combinatorics teaching were identified: synthesizing instance, dialogic instance and contradictory instance. We conclude that different teachers' instances about validation of solutions expresses in different conceptions of combinatory teaching, with implications on the way mathematics is taught and evaluated.
\end{abstract}

KEYWORDS: Teachers' Education. Combinatory. Teachers' Conceptions and Beliefs. Analyzing problems' solution.

Entendendo criterios de validación para los problemas de Combinatoria utilizados por los profesores de Educación Básica

\title{
RESÚMEN
}

Este artículo analiza las concepciones y creencias de los profesores sobre la validez de diferentes soluciones a un problema de Combinatoria. Esta investigación se justifica porque: (i) los problemas de Combinatoria pueden presentar una serie de soluciones que involucran diferentes formas de pensar; (ii) los docentes valoran las soluciones basadas en razonamientos estandarizados, considerando muchas veces soluciones correctas inválidas porque no encajan en estos modelos y (iii) comprender las concepciones y creencias de estos docentes puede servir para establecer estrategias, tanto en la educación inicial como en la continua, reconocer y valorar el razonamiento no estándar. Se realizaron entrevistas semiestructuradas 
con cuatro sujetos preseleccionados, los cuales fueron analizados según Análisis de Contenido, y luego de sucesivas categorizaciones, se identificaron tres posturas respecto a la enseñanza de contar, derivadas de las entrevistas: posturas sintetizadoras, dialógicas y contradictorias. Concluimos que diferentes actitudes sobre la validación de soluciones se expresan en conceptos de enseñar a contar en el aula, con implicaciones para qué forma de enseñar y evaluar las matemáticas se presentará a los estudiantes.

PALABRAS CLAVE: Formación del profesorado. Combinatoria. Concepciones y Creencias. Análisis de soluciones de problemas.

$$
* * *
$$

\section{Introdução}

Apesar de ser um conteúdo recomendado pelos documentos oficiais para ser trabalhado desde as séries iniciais e durante toda a formação básica, nossa experiência enquanto docente da educação básica e formadora de professores, nos fazem crer que, frequentemente, o assunto contagem só é trabalhado no Ensino Médio, no tópico Análise Combinatória. Com isso, perdem-se várias oportunidades de desenvolver o raciocínio combinatório na escola, tornando-o assunto contagem descontextualizado das outras experiências da matemática escolar.

Contagem pode ser um assunto desafiador, haja vista a variedade de possíveis heurísticas na resolução dos problemas, a dificuldade em estimar se um resultado é correto ou não e, não menos importante, falhas na formação dos professores de matemática que podem redundar na persistência de visões limitantes sobre o que é válido ou não como solução de um problema de contagem.

Pesquisas e experiências (PESSOA \& BORBA, 2009; 2010) nos mostram que mesmo crianças no ensino fundamental I (primeiro ao quinto ano de escolaridade) podem realizar atividades de contagem e resolver problemas, com base em suas próprias estratégias de cálculo. Para essas autoras, o desenvolvimento conceitual do raciocínio combinatório "é um modo 
especial de pensamento lógico-dedutivo e, em uso pleno, denota um mais alto nível de desenvolvimento cognitivo" (BORBA, PESSOA \& ROCHA, 2013, p. 896).

Entendemos Contagem como estratégias e meios para quantificar padrões ou subconjuntos de objetos ou de situações, a partir de um conjunto dado. Para isso, pode-se munir de estratégias (árvores, fórmulas, diagramas etc.) para determinar quantos elementos ou quantos eventos são possíveis numa dada situação, sem precisar contá-los um a um. Essas estratégias, baseadas no raciocínio multiplicativo e aditivo, organizam sistematicamente grupos de possibilidades para resolver certos tipos de problema, como a constituição de agrupamentos, a determinação de possibilidades e sua contagem. Optamos por uma definição ampla para este conceito, para abarcar experiências de contagem desde os anos iniciais de formação, até aquelas que usualmente são chamadas de Análise Combinatória: Arranjo, Permutação, Combinação e outras técnicas que utilizam o princípio fundamental da contagem e o princípio da adição.

Especificamente sobre a formação inicial de professores, a contagem figura (ou figurou, para boa parte dos professores na ativa), em muitos cursos de licenciatura em matemática, ou como uma disciplina optativa ou um conteúdo dentro de uma disciplina obrigatória - como cálculo de probabilidades ou matemática finita. Isso faz com que seja frequente considerar esse conteúdo como um pré-requisito, não sendo revisitado com o objetivo de discutir as especificidades de ensiná-lo na educação básica. Com base nisso, acreditamos que as concepções e crenças dos professores que começam a lecionar esse conteúdo são fortemente influenciadas pelas suas experiências enquanto alunos da educação básica, mantendo critérios de validação - "essa solução é correta”? "O raciocínio utilizado para resolver esse problema é adequado"? "Qual fórmula encaixa nesse problema”? - que não remetem a uma problematização específica desse conteúdo em situações de ensino em sua formação para a docência. Essa afirmação é corroborada por Borba, Rocha e Lima (2016): 
O professor, em particular o de Matemática, desenvolve-se, enquanto profissional, a partir dos conhecimentos teórico-práticos adquiridos ao longo de sua formação. Enquanto estudante e, posteriormente, no exercício da docência, o professor apreende conhecimentos referentes aos diversos conteúdos que trabalhará em sala de aula e concernentes aos processos de ensino e de aprendizagem desses conteúdos. Dentre esses conhecimentos, há os mais amplos - sobre as dinâmicas dos espaços escolares, por exemplo - e há conhecimentos sobre aspectos específicos de determinados conceitos trabalhados. (BORBA et al, 2016, p, 235)

Concepções limitantes sobre a validade de raciocínios envolvidos nas contagens podem ser uma barreira à variedade dos problemas apresentados na educação básica, fazendo com que o professor desconsidere raciocínios válidos - e matematicamente corretos - apresentados pelos alunos e passe ao largo do que deveria ser mais importante: despertar nos estudantes as habilidades de raciocínio necessárias para identificar situações em que a contagem é utilizada e realizar operações corretas, dentro desses contextos. De acordo com Santos (2011, p. 72): “(..) o que ocorre, com frequência, no ensino da Análise Combinatória no ensino médio, é o uso excessivo de práticas manipulativas, levando o aluno à mecanização de processos", com isso "criase a falsa impressão de que a Análise Combinatória é somente um jogo de fórmulas complicadas" (MORGADO et al., 2004, p. 2).

Desde os PCN's, a importância da contagem é reconhecida:

A contagem, ao mesmo tempo que possibilita uma abordagem mais completa da probabilidade por si só, permite o desenvolvimento de uma nova forma de pensar em Matemática, denominada raciocínio combinatório. Ou seja, decidir sobre a forma mais adequada de organizar números ou informações para poder contar os casos possíveis não deve ser aprendido como uma lista de fórmulas, mas 
como um processo que exige a construção de um modelo simplificado e explicativo da situação (BRASIL, 2002, p. 126).

Mais recentemente, com a Base Nacional Comum Curricular (BRASIL, 2019), tem se valorizado o ensino de contagem desde os primeiros anos do ensino fundamental, propondo sua integração ao currículo com habilidades e competências adequadas a cada fase do ensino.

Acreditamos que o ensino de contagem deve ir além de concepções meramente procedimentais e trabalhar, sempre que possível, com o desenvolvimento do raciocínio combinatório por si mesmo. Mas abre-se assim uma questão: será que os professores atuantes no ensino básico valorizam esse processo?

Esse artigo investiga que concepções e crenças emergem das interações de professores atuantes na educação básica a partir de diversas soluções de problemas de contagem. Para isso, foram selecionados e entrevistados quatro professores com diferentes formações e experiências com ensino de contagem. Eles foram instados a resolver um problema, analisar e avaliar quatro soluções fictícias (mas prováveis) de alunos para esse problema e apresentar um comentário que eles fariam ao aluno, caso estas aparecessem em uma avaliação proposta por eles. Foram identificadas três posturas acerca do ensino de contagem, oriundas das entrevistas: postura sintetizante, dialógica e contraditória, que serão descritas na seção de análise dos dados.

Para entender essas posturas, usaremos como base os trabalhos de Borba e colaboradores (PESSOA \& BORBA, 2009; 2010; BORBA, 2010) que pesquisam há algumas décadas sobre o ensino de análise combinatória e contagem, bem como concepções e crenças de professores acerca desse conteúdo na educação básica. Como metodologia para a construção das questões de contagem apresentadas aos entrevistados, usamos uma abordagem inspirada nas MathTASK's (BIZA et al, 2018). Já a análise dos dados teve como base a Análise de Conteúdo (BARDIN, 2004). 


\section{MathTASK}

Biza et al (2018) propõem MathTASK como metodologia para ir além da discussão abstrata de crenças sobre as práticas de ensino. Defendem que um contexto concreto pode dar uma compreensão compartilhada entre pesquisadores sobre essas crenças, o que pode ajudar a evoluir a pesquisa. A metodologia MathTASK é composta de quatro etapas:

(a) Resolução de um problema matemático;

(b) Avaliação de uma solução proposta, real ou fictícia, realizada por um aluno em sala;

(c) Avaliação da interação de outro professor com o aluno que apresentou a solução;

(d) Descrição da abordagem que os professores utilizariam em sala nessa situação.

O problema, as soluções do aluno e a intervenção do professor precisam ser ancoradas em pesquisas, de modo a evidenciar situações que têm reconhecidas dificuldades de aprendizagem. $O$ objetivo principal das MathTASKs é tentar entender como os professores reagiriam numa situação real - e provável - de sala de aula quando fossem ensinar esse tipo de conteúdo, a partir da reflexão sobre a interação entre aluno e professor.

Segundo os autores, não é suficiente que as quatro etapas descritas acima sejam seguidas para que se configure uma MathTASK. Para isso, é preciso que: (i) o conteúdo matemático relativo ao tópico estudado cause alguma dificuldade aos estudantes; (ii) as respostas apresentadas dos estudantes representam erros que podem ser realizados e permitam ao professor refletir e demonstrar formas que ele poderia agir para resolver essas dificuldades; (iii) a abordagem pedagógica utilizada pelo professor da etapa (c) da MathTASK pode ser considerada desafiadora aos professores que a estão respondendo; (iv) as respostas e o conteúdo matemático proporcionam contextos para emergir os conhecimentos dos professores, suas crenças e ajudar a compreender detalhes sobre suas práticas. 
Em nosso caso, especificamente, optamos por não apresentar o item (c) (avaliação da interação de outro professor com o aluno que apresentou a solução) devido às características dos professores que foram selecionados por nós. Alguns dos prováveis sujeitos a serem entrevistados tinham pouca experiência com ensino de contagem, já que atuam preferencialmente no ensino fundamental. Acreditamos que a resposta de outro professor poderia influenciar nas respostas desses professores, fazendo com que eles concordassem com elas sem reflexão. Assim, entendemos que não realizamos MathTASK com os entrevistados, mas uma abordagem inspirada e muito próxima que ajudou a evidenciar algumas concepções e crenças desses professores, analisadas neste trabalho.

\section{Objetivo e descrição}

Queremos identificar, compreender e analisar as concepções e crenças de professores atuantes na educação básica sobre a validade ou não de soluções não-padronizadas de problemas de contagem. Para isso, foram selecionados e entrevistados quatro professores participantes do curso de extensão Jogos \& Matemática, realizado na Universidade Federal do Estado do Rio de Janeiro (UNIRIO). O curso contou com aproximadamente 110 participantes, entre professores e alunos de graduação e os encontros presenciais ocorreram mensalmente. A principal atividade do curso foi a construção e discussão de jogos pedagógicos que podem ser utilizados na educação básica. Dentre os resultados concretos do curso de extensão, há um site (https://jogosmatunirio.wordpress.com/) em que os modelos e regras dos jogos podem ser baixados e algumas atividades são propostas.

Cada entrevista semiestruturada foi gravada e transcrita, e tratou sobre a formação inicial desses professores, seu trabalho atual e a análise deles acerca de respostas a um problema de contagem. A pesquisa foi submetida ao Comitê de Ética em Pesquisa da UNIRIO sob o título "Análise de concepções e crenças de professores de matemática sobre a validade de 
soluções de problemas apresentados envolvendo o princípio fundamental da contagem" e CAAE 93048418.0.0000.5285.

Para a seleção dos entrevistados, foi pedido a todos os cursistas para resolverem um problema de contagem, semelhante ao que seria tratado na entrevista, além de comentarem a solução de um aluno para outro problema. As respostas dos cursistas foram classificadas como certas/erradas e organizadas com base na valorização de estratégias baseadas em fórmulas (um extremo), até valorização de explicações não-formais (outro extremo). Com as respostas dos cursistas assim organizadas, as soluções foram divididas em quatro grupos de mesmo tamanho e selecionado um respondente de cada grupo que satisfizesse os requisitos para ser entrevistado: estar trabalhando com educação básica e ter terminado o curso de licenciatura em Matemática. Essa separação é importante, pois no curso havia professores das séries iniciais (licenciados em pedagogia) bem como alunos de licenciatura em Matemática.

A decisão dos pesquisadores de restringir a pesquisa a professores de matemática se justifica pela dificuldade da questão proposta para ser analisada pelos professores, bem como para permitir que contribuições oriundas da prática docente pudessem emergir das entrevistas. Vinte e quatro sujeitos atenderam a estes critérios, donde veio o universo que os quatro entrevistados foram selecionados.

FIGURA 1: Questão Respondida pelos Entrevistados.

Questão: Jair resolveu vender alguns dos livros que tem em casa para poder ganhar um pouco de espaço na estante da sala. Ele possui sete livros de matemática, nove livros de literatura brasileira e dez biografias. No total, ele quer de desfazer de cinco livros. De quantas formas ele pode fazer isso?

Após responder à questão, cada entrevistado comentou quatro soluções diferentes (conforme Figura 2), que lhe foram apresentadas em ordem 
aleatória. Eles deram uma nota, de zero a dez, e fizeram um comentário/intervenção pedagógica que seria realizada por ele em sala.

FIGURA 2: Soluções apresentadas para avaliação dos entrevistados.

Solução 1:

$$
\frac{7 \cdot 9 \cdot 10}{5}=315 \text { Maneiras }
$$

Solução 2:

Eu pensei da seguinte maneira: temos 7 livros do tipo $x, 9$ do tipo y e 10 do tipo z. Temos que escolher um total de cinco livros. Podemos escolher cinco do primeiro tipo e nenhum dos outros $2 ; 4$ do primeiro tipo, um do segundo e nenhum do terceiro; 4 do primeiro tipo, nenhum do segundo e um do terceiro e assim sucessivamente, até nenhum do primeiro, nenhum do segundo e cinco do terceiro. Como "a ordem" dos livros não importa dentro de um determinado tipo, temos que isso é feito de:

$$
\left(\begin{array}{l}
7 \\
5
\end{array}\right) \cdot\left(\begin{array}{l}
9 \\
0
\end{array}\right) \cdot\left(\begin{array}{c}
10 \\
0
\end{array}\right)+\left(\begin{array}{l}
7 \\
4
\end{array}\right) \cdot\left(\begin{array}{l}
9 \\
1
\end{array}\right) \cdot\left(\begin{array}{c}
10 \\
0
\end{array}\right)+\left(\begin{array}{l}
7 \\
4
\end{array}\right) \cdot\left(\begin{array}{l}
9 \\
0
\end{array}\right) \cdot\left(\begin{array}{c}
10 \\
1
\end{array}\right)+\cdots+\left(\begin{array}{l}
7 \\
0
\end{array}\right) \cdot\left(\begin{array}{l}
9 \\
0
\end{array}\right) \cdot\left(\begin{array}{c}
10 \\
5
\end{array}\right)
$$

Eu sei que o meu raciocínio é coerente, mas nessa prova não vou ter tempo de fazer todas as contas.

Solução 3:

Como temos $7+9+10=26$ livros, podemos imaginá-los como um conjunto só de livros dos quais vamos selecionar cinco, cuja ordem não importa. Isso pode ser feito de:

$$
\left(\begin{array}{c}
26 \\
5
\end{array}\right)=\frac{26 !}{5 ! 21 !}=\frac{26 \times 25 \times 24 \times 23 \times 22}{5 \times 4 \times 3 \times 2 \times 1}=26 \times 5 \times 8 \times 23 \times 11=65780 \text { maneiras }
$$

Solução 4:

Pelo princípio multiplicativo, o primeiro livro pode ser escolhido de 26 maneiras $(7+9+10)$. 0 segundo, de 25 , e assim sucessivamente. Como a ordem dos livros não importa, vamos dividir por 5 .

$$
\frac{26 \times 25 \times 24 \times 23 \times 22}{5}=1578720
$$

A solução 1 está errada. As quantidades de livros foram multiplicadas $(7 \cdot 9 \cdot 10)$ e o resultado foi dividido por 5 (a quantidade de livros que deve ser descartada). Essa solução pode significar que o aluno utilizou o princípio fundamental da contagem de maneira errada, colocando todos os dados do problema em uma expressão e fazendo a conta. Utilizar os dados do problema para apresentar uma solução é um erro comum e largamente estudado, como 
no problema da Idade do Capitão (BARUK, 1985), o que justifica que essa solução faça parte do nosso rol de possibilidades.

A solução 2 apresenta uma maneira de pensar no problema que envolve dividi-lo em partes e somar as possibilidades, utilizando o princípio da adição. Conceitualmente, ela está correta. O princípio multiplicativo e a aplicação da combinação também estão corretos, bem como a explicação da maneira que foi pensada está satisfatória. Porém, o resultado não foi apresentado e o suposto aluno utiliza a notação de combinação simples, mas não explicita como o cálculo é feito em cada caso. Essa solução foi pensada para identificar se os critérios de validação das soluções dos entrevistados contemplam casos em que o aluno não deu uma resposta numérica, mas utilizou raciocínio correto/coerente.

A solução 3 está correta. Ela é apresentada com uma breve explicação do raciocínio e os dados do problema são inseridos em uma fórmula "pronta". As contas estão explicitadas, bem como o resultado. Essa é a solução que, comumente, é considerada a solução esperada, ou a solução minimizada.

Por fim, a solução 4 é organizada com base no princípio multiplicativo, mas está incorreta porque não desconta todas as possiblidades de permutar os livros. Se são selecionados cinco livros $(A, B, C, D, E)$, existem 5 ! maneiras de organizá-los que correspondem à mesma seleção de livros. Portanto, se $R$ é o resultado que estamos buscando,

$$
R \times 5 !=26 \times 25 \times 24 \times 23 \times 22 \Rightarrow R=\frac{26 \times 25 \times 24 \times 23 \times 22}{5 !}
$$

Como a solução apresentada está dividida por 5 , não está totalmente correta. A solução 4 foi incluída tentando compreender que peso é dado pelos entrevistados para erros conceituais no contexto de uma solução enxergada por nós autores como parcialmente correta.

Nas quatro soluções, buscamos mostrar diferentes heurísticas que podem ser utilizadas por alunos para resolver o problema dado e que fossem possíveis de aparecerem nas salas de aula dos sujeitos.

Os quatro entrevistados (todos homens) têm seus perfis apresentados no quadro 1. Seus nomes foram alterados, para evitar sua identificação. Todos 
eles responderam ao problema antes de serem apresentados às quatro soluções. Agnaldo e César responderam exatamente como a solução 3, fazendo a combinação de 26 elementos tomados 5 a cinco. Daniel resolveu o problema como apresentado na solução 2, abrindo em várias combinações, mas sem calcular o resultado. Já Bruno, apresentou a solução 1, incorreta.

QUADRO 1: Descrição dos Sujeitos

\begin{tabular}{|l|l|l|l|l|l|}
\hline Nome & \multicolumn{1}{|c|}{ Formação } & $\begin{array}{l}\text { Experiência } \\
\text { Profissional }\end{array}$ & $\begin{array}{l}\text { Já deu aula de } \\
\text { combinatória? }\end{array}$ & \multicolumn{1}{|c|}{ Rede } & $\begin{array}{c}\text { Segmento de } \\
\text { atuação }\end{array}$ \\
\hline Agnaldo & $\begin{array}{l}\text { Pública / } \\
\text { mestrado em } \\
\text { andamento }\end{array}$ & 7 anos & Várias vezes & Privada / estadual & $\begin{array}{l}\text { Fundamental II } \\
\text { e Médio }\end{array}$ \\
\hline Bruno $^{3}$ & Privada & 2 anos & Nunca & Privada & Fundamental I \\
\hline César & Pública & 9 anos & Às vezes & $\begin{array}{l}\text { Privada / } \\
\text { municipal }\end{array}$ & $\begin{array}{l}\text { Fundamental II } \\
\text { e Médio }\end{array}$ \\
\hline Daniel & $\begin{array}{l}\text { Privada } \\
\text { /mestrado em } \\
\text { andamento }\end{array}$ & 16 anos & Várias vezes & Estadual & Ensino Médio \\
\hline
\end{tabular}

Na solução 1, Agnaldo, Bruno e César deram nota zero, mas por motivos diferentes, como veremos à frente. Já Daniel deu nota 3. Agnaldo disse que houve um erro conceitual e, por isso, não pode considerar a solução. Porém, atuaria com o aluno explicando o erro e tentando conduzi-lo ao raciocínio correto. Bruno disse que a conta foi armada direito, mas que, como ele errou na hora de fazer os cálculos, ele daria errado. De fato, o resultado da conta é 126. César não entendeu o que o aluno fez. Disse que não daria nota e pediria para o aluno explicar seu raciocínio. Já Daniel disse que o raciocínio está errado, mas daria uma pequena pontuação porque ele usou o princípio multiplicativo.

Na solução 2, Agnaldo e César deram nota 10. Bruno deu 5 e Daniel não entendeu a solução e não deu nota. Agnaldo comentaria com o aluno que a solução está certa, mas que há um caminho que pode fazer menos contas, imaginando juntar os livros todos em uma pilha só. César compreendeu o que o aluno fez, viu que foi diferente de sua solução e achou a melhor resposta.

\footnotetext{
${ }^{3}$ Bruno se formou há mais de uma década, mas só recentemente voltou a trabalhar como professor.
} 
Seu comentário seria reforçando a criatividade do aluno. Bruno daria cinco porque achou a solução "muito grande", mostrando que valoriza soluções otimizadas:

Bruno4: [pensa, põe a mão na cabeça, coça o nariz]. Eu daria 5 para ele [parece incerto] porque aqui ele utilizou uma fórmula muito grande... uma forma muito grande de raciocínio sem dar o resultado Entrevistador: Mas aí você entendeu como ele foi fazendo? [Aponta no papel dele] Combinação de cinco elementos tomados zero a zero, quatro tomados $1 \mathrm{a}$ um e assim sucessivamente...

Bruno: [Assente, faz sinal de muito grande com as mãos] Só que ele utilizou um cálculo muito grande. Ele poderia ter sido mais resumido.

Entrevistador: Então isso que você falaria para ele? [Confirma com a cabeça] ... que o cálculo é muito grande e que...

Bruno: Isso!

Entrevistador: Beleza.

Note que o entrevistador, percebendo algum tipo de confusão de Bruno, busca explicar a solução para esclarecer se ele entendeu ou não a solução. Bruno confirma que entendeu a notação e o cálculo, mostrando que não reconhece a solução por ser muito grande.

Já Daniel não percebeu que a solução do aluno foi equivalente à sua, pois a notação $(n p)$ utilizada na solução era diferente da que ele conhecia para cálculo de combinações. Ele disse que não entendia "de Binômio de Newton":

Daniel: Sendo bem sincero pela minha fraqueza, eu não sei te responder, até porque embora análise combinatória precise de binômio de Newton, eu não me acho confiável em binômio de Newton.

\footnotetext{
${ }^{4}$ Nessa e em todas as outras transcrições das falas dos sujeitos optamos por manter a grafia original, inserindo elementos de contexto, como pausas e movimentos captados pelo vídeo.
} 
Daniel enxerga que não saber Binômio de Newton é, segundo suas próprias palavras, uma "fraqueza", já que números binomiais fazem parte do currículo do ensino médio. Porém, ele não associa os números binomiais com as combinações, como se fizessem parte de lugares distintos dentro do currículo da matemática.

Na solução 3, Agnaldo e César deram nota 10, ambos achando a solução satisfatória. Lembramos que essa é justamente a solução apresentada por eles. Bruno deu nota 7 , dizendo que a solução parecia a mais correta.

Entrevistador: 0 a 10 que nota você daria para essa questão?

Bruno: De 0 a 10 ?

Entrevistador: Uhum.

Bruno: 7.

Entrevistador: Como é que você falaria para o aluno uma maneira dele corrigir esse erro? Que comentário você faria?

Bruno: [Pensa por vinte segundos] $\mathrm{Na}$ verdade, nessa avaliação ficaria difícil avaliando, porque eu não estou dando o conteúdo. Então a nota mesmo seria justo... 7. Não domino o conteúdo então seria difícil a avaliação aqui.

Mas o que leva Bruno a dar uma nota, mesmo se sentindo inseguro com o conteúdo? Ao que parece, ele sabe reconhecer que uma solução de um problema de contagem deve ser verdadeira pela forma que ela é apresentada. Bruno valoriza uma certa forma de escrever a solução, minimizada, e que deve ser bem pontuada mesmo que ele não tenha certeza de que ela está certa. Após o entrevistador explicar a solução, ele mudou a nota para 10.

Daniel deu 6, porque não entendeu a solução do aluno. Para ele, não fazia sentido pensar em 26 livros como um conjunto só. Com efeito, após o entrevistador tentar explicar a Daniel como o aluno poderia ter pensado, ocorre a seguinte interação: 
Entrevistador: Então você dá nota 6 pra ele. E o que falta para ele ganhar 10 ?

Daniel: na verdade, observando o número de possibilidades de questões de livros que ele pode ter. Essa questão aqui, ele está pegando o somatório das questões que ele tem. 5 livros para poder comprar. O que eu insisto na questão é: Quais os livros que você quer saber? Poderia dividir de todas essas maneiras, como você poderia dividir essas coleções que te interessam com 5 livros então?

Por fỉm, na solução 4, Agnaldo deu nota 4, Bruno não deu nota, César deu 9 e Daniel deu 8,5. Agnaldo considerou um erro grave dividir por 5 e não por 5!. Utilizaria exemplos para mostrar para o aluno o que deveria ter descontado. Bruno não entendeu a solução e, após intervenção do entrevistador, deu nota 7, porque achou parcialmente correta. César gostou da utilização do princípio multiplicativo e acha que não colocar o 5! foi um erro menor. Já Daniel achou que o erro foi apenas o 5 no denominador e que a resposta correta seria $26 \times 25 \times 24 \times 23 \times 22$.

A Análise do Conteúdo das entrevistas gerou três categorias: validade das soluções, critérios de avaliação e metodologias de ensino relatadas. Com base nessas categorias, identificamos três posturas dos professores: sintetizante, dialógica e contraditória. As posturas foram identificadas pela análise cruzada das três categorias emergentes das entrevistas. Como veremos a seguir, na descrição de cada uma das posturas, é avaliando a resposta do entrevistado para a validade da solução (positiva ou negativa) e os critérios de avaliação apontados oralmente ou por escrito em contraposição às metodologias de ensino valorizadas e descritas pelos entrevistados que poderemos identificar se dado sujeito se aproxima de uma postura ou de outra.

Para analisar essa validade, levamos em conta as respostas consideradas certas ou erradas pelos respondentes, seus comentários em cada solução e a concordância ou não entre as soluções realizadas pelos 
entrevistados e aquelas que foram avaliadas, gerando um quadro comparativo entre os quatro entrevistados.

A sintetizante se refere a uma postura do professor de matemática de validar, em sua avaliação, raciocínios minimizados. A validade e correção se assentam em critérios como "solução mais curta" ou "mais elegante". O entrevistado que se encaixa nessa postura acredita que, quando há um problema matemático a ser resolvido, existe uma solução ótima a ser perseguida, que tem as seguintes características: (i) é uma solução curta e matematicamente correta; (ii) para chegar a ela, é preciso identificar um padrão de resolução deste tipo de problema e encaixar suas características numa heurística, considerada ótima, o que pode significar adaptar o problema a uma fórmula; (iii) pedagogicamente, o professor busca que todos os alunos se aproximem dessa solução, avaliando os alunos com base na sua adesão ou não ao seu sistema. Essa postura envolve um ensino homogeneizante. Num mundo ideal, todos os alunos darão variações próximas da mesma resposta, que é considerada a única correta.

Dentre nossos entrevistados, Bruno foi identificado com essa postura. Ele é o professor com menos experiência docente e ainda não teve a oportunidade de dar aula de contagem para seus alunos. Porém, a adesão a essa postura não é ligada ao conteúdo (no caso, contagem) mas a atividades e posturas docentes identificadas ou relatadas. De fato, quando perguntado sobre uma aula sua que deu certo, Bruno descreveu:

[...] lá na escola, como tinha um parquinho falei praquela galera toda para pegar a tabuada. Eu falava que na minha próxima aula vai ser tabuada de 8 e 9. "Pessoal vai para o parquinho quem acertar a tabuada”. Então foi uma aula que com certeza deu certo, que até hoje eu vejo alunos que estão até formados na AMAN, ensino superior completo... Me encontra na rua e fala: "Caraca, professor, aquele parquinho! Foi o que marcou”. 
Percebe-se uma postura de valorização de uma resposta certa. Os alunos que acertavam a tabuada tinham uma recompensa imediata: a possibilidade de ir para o parquinho brincar. Ao mesmo tempo, os alunos que erravam eram punidos, permanecendo na sala. Essa postura se reflete também na hora de resolver o problema: sua solução é uma conta com os números do problema, utilizando o princípio multiplicativo de uma maneira errada. Quando ele se depara com uma solução equivalente à sua - mas matematicamente errada - ele dá nota zero, mas não por ter identificado o erro matemático, mas porque o aluno errou as contas.

Reiteramos que o que importa, para nossa análise, não é se o professor acertou o problema ou não. A experiência de Bruno com contagem vem só de sua graduação e é natural que ele tenha alguma dificuldade para resolver um problema que não está acostumado. Nos interessam os critérios de validação e as posturas quando apresentado a soluções não-padronizadas. Por exemplo, quando apresentado à solução 2 , Bruno disse que "Eu daria 5 para ele porque ele utilizou uma fórmula muito grande de raciocínio sem dar o resultado”. Ou seja, Bruno valoriza uma resposta, um número, uma conta que apresente a solução do problema de maneira otimizada.

A postura dialógica está ligada a um comportamento docente de valorização das respostas e heurísticas dos alunos para intervenção pedagógica. É uma postura centrada no aluno, uma busca de entender sua maneira de pensar, dando peso para raciocínios que podem não ser padronizados ou minimizadores, no sentido descrito na postura anterior. Professores que se encaixam nesse perfil costumam usar o próprio raciocínio do aluno como base para intervir, fazendo perguntas, propondo pensamentos análogos, para gerar contradições, ou pedindo para os alunos darem exemplos de como estão pensando no problema.

Tais professores não buscam que todos os alunos resolvam o problema de mesmo modo, mas que criem suas próprias técnicas. Sua didática busca, antes, que todos tenham raciocínios matemáticos corretos e coerentes e que 
construam suas próprias interpretações e soluções, adequadas a cada contexto de problema.

$\mathrm{Na}$ nossa pesquisa, dois professores se encaixaram nessa categoria: Agnaldo e César. Perguntado sobre uma aula sua que deu certo, Agnaldo relata:

Eu tenho costume de não começar já na definição. Eu não gosto disso! Eu tenho aversão esse troço! Então eu dei um problema, um problema que é bem conhecido no mundo da gente, que é um problema dos apertos de mão. A ideia do problema é seguinte: tinha uma festa, tinha uma certa quantidade de pessoas que tinha que descobrir qual é. E a única coisa que a gente sabia era o total de apertos de mão. E nesse caso, nessa festa, eram 66 apertos de mão. Aí eu fui conduzindo, querendo saber quantas pessoas tinham nessa festa.

Agnaldo segue descrevendo a atividade, mostrando como seus alunos foram buscando soluções para o problema: indo ao quadro, fazendo conjecturas, discutindo entre si, até que a turma toda tivesse um consenso sobre a quantidade de pessoas na festa. Essa atividade foi realizada justamente para introduzir o conteúdo de análise combinatória e revela uma postura de valorização das produções dos alunos.

Já César descreveu uma atividade que ele utilizou em sala com materiais concretos, com os alunos fazendo conjecturas e tabelas a partir de sólidos de Platão. Também partiu das respostas dos alunos para que eles percebessem o padrão da relação de Euler.

Isso também se reflete na hora de avaliar as soluções. Tanto Agnaldo quanto César deram nota máxima para a solução 2 , que envolve a soma de várias combinações. Sobre a solução do aluno, Agnaldo diz:

Agnaldo: Ah, mas ele fez! O mais difícil na minha opinião ele fez! O mais difícil que é conjecturar isso aqui. Ele pensou: "bom se eu escolho 5 de matemática, beleza. Eu escolhi meus 5”, depois [...] 
quebrou em casos. Fez caso 1, caso 2... é o que eu tô entendendo. Depois somou os casos. Tá certo!

Entrevistador: Então você daria 100\%?

Agnaldo: 100\% [assertivo]

O professor demonstra empolgação com uma resposta do aluno, que não era a esperada por ele. Não faz nenhuma menção a descontar ponto por não ter encontrado a resposta numérica. E, mais à frente, quando perguntado sobre a intervenção pedagógica, busca ter certeza de que o aluno entendeu o conceito de combinação. Na mesma questão, César diz:

Entrevistador: Você entendeu o que ele fez, né?

César: Sim, ele tá abrindo todas as possibilidades.

Entrevistador: Mas ele não chegou na resposta no final.

César: É muita conta.

Entrevistador: Então você daria 10 nesse caso?

César: É! O raciocínio está certo.

Entrevistador: algum comentário para ele?

César: tá de parabéns.

César, assim como Agnaldo, valoriza um diálogo com o aluno, tentando entender com ele o seu jeito de resolver o problema.

A última postura identificada foi a contraditória. Daniel parece valorizar raciocínios dos alunos, por exemplo, dando uma pequena pontuação na solução 1, por identificar o princípio multiplicativo. Na entrevista, ele falou sobre experiências dele em sala, usando jogos e material concreto, mas quando perguntado se esse tipo de atividade era comum, ele deu uma resposta contraditória:

Daniel: eu acho que tem que unir o útil ao agradável. É impossível a gente descartar um pouco conservador e tentar colocar o moderno. Porque quando você colocar o moderno, você causa discórdia. 
Quando você coloca o conservador, você se torna obsoleto. Acho que a ideia é unir o útil ao agradável.

Perceba que sua fala é confusa. É difícil entender sua posição, pois ele se coloca entre polos não necessariamente antagônicos (moderno/conservador discórdia/obsoleto). Ele parece não querer se comprometer. Quando perguntado sobre a solução 3, ele não entende a solução do aluno e mesmo depois de explicado, disse que daria nota parcial. Achamos que isso é grave já que, mesmo sendo professor há bastante tempo e dando esse conteúdo várias vezes, Daniel não foi capaz de identificar um raciocínio correto. Em vez disso, ele tentou fazer com que o aluno "se encaixasse" na sua solução. Portanto, César tem um discurso que valoriza as produções dos alunos, dando alguma nota para produções parciais, mas uma avaliação que remete a uma solução correta, ideal, e que deve ser buscada pelos alunos. Enxergamos, assim, sua postura como contraditória, não tendo elementos, com base nos dados, para uma conclusão acerca de suas práticas em sala.

\section{Conclusões e apontamentos}

Retornando à nossa questão de pesquisa, gostaríamos de compreender e analisar a concepções e crenças de professores atuantes na educação básica sobre a validade ou não de soluções não-padronizadas de problemas de contagem. O desenvolvimento da pesquisa, principalmente a fase de análise das entrevistas, permitiu identificar posturas, dentro do conjunto de sujeitos analisados, frente às soluções apresentadas. O processo de recategorização, típico da Análise de Conteúdo, permitiu identificar três categorias emergentes da entrevista: validade das soluções, critérios de avaliação e metodologias de ensino relatadas. A identificação das três posturas (sintetizante, dialógica e contraditória) foi resultado da análise cruzada das enumerações identificadas em cada sujeito em cada categoria. 
A estrutura de investigação proposta permitiu emergir posturas sobre a validade de soluções de professores. Identificadas três posturas em relação a essa validade, foram dados exemplos de como os critérios de validação das soluções dos alunos refletem concepções que os professores possuem sobre o que é ensinar matemática. As posturas sintetizante, dialógica e contraditória emulam concepções e crenças desses professores que emergem de suas práticas relatadas e da interação deles com soluções prováveis de alunos.

Não temos aqui a pretensão de descrever pormenorizadamente as concepções e crenças desses sujeitos (nem mesmo as posturas deles frente às soluções de problemas de combinatória), mas apontar que existe uma diversidade de posturas dos professores em relação a essas soluções. Identificamos, sim, as "práticas manipulativas" e "mecanizadas" apontadas por Santos (2011), associadas à postura sintetizante, mas também a valorização do raciocínio combinatório nos professores que foram identificados com a postura dialógica. A relação entre sua experiência e sua prática docente no ensino de combinatória já era apontada por Rocha (2011).

Acreditamos que a metodologia aqui utilizada pode ter um papel importante como modelo para compreender as práticas de professores, mas que ainda é necessário realizar mais pesquisas, tanto para identificar e classificar as posturas dos professores frente ao ensino de contagem, como para compreender de que forma a formação - inicial e continuada - de professores pode ser planejada para trabalhar com exemplos práticos do que ocorre em sala de aula, não só do ponto de vista dos conhecimentos mobilizados (como, por exemplo, analisado por Rocha (2011).

Acreditamos que esse é apenas um começo de conversa. Por exemplo, cremos que essa pesquisa possa ser estendida a um número maior de professores para avaliar a perenidade e completude das posturas aqui identificadas. Também seria interessante avaliar como a formação continuada pode influenciar na mudança dessas posturas. A quantidade relativamente baixa de pesquisas enfocada no ensino de contagem nos anos finais da educação básica aponta que é preciso expandir as investigações para 
dar suporte à necessidade de ensinar a contagem e o raciocínio combinatório de maneira distribuída no currículo da escola básica, a partir das demandas da BNCC.

Por fim, cremos que é preciso investigar sobre o uso das MathTASK's como ferramentas para formação inicial e continuada de professores, tanto no ensino de contagem, quanto em outros tópicos da matemática básica. A estrutura de discussão com base em um problema inspirado ou oriundo da interação em sala de aula pode suscitar discussões que mobilizem saberes compartilhados entre professores de diferentes experiências e locais de trabalho, com resultados tangíveis para a formação.

\section{Referências}

BARDIN, L. Análise de conteúdo. 3a . Lisboa: Edições, v. 70, 2004.

BARUK, S. L'âge du capitaine. De l'erreur en mathématiques. Paris, Le Seuil, 1985.

BIZA, I.; NARDI, E.; ZACHARIADES, T. Competences of mathematics teachers in diagnosing teaching situations and offering feedback to students: Specificity, consistency and reification of pedagogical and mathematical discourses. In:

Diagnostic Competence of Mathematics Teachers. Springer, Cham, 2018. p. 55-78.

BRASIL. Secretaria de Educação Média e Tecnológica. PCN+ Ensino Médio:

Orientações Educacionais Complementares aos Parâmetros Curriculares Nacionais. Brasília: MEC, 2002.

Ministério da Educação. Base Nacional Comum Curricular. Brasília, DF: MEC, 2019. Disponível em:

$<$ http://basenacionalcomum.mec.gov.br/documento/BNCC-APRESENTACAO.pdf>. Acesso em: 08 abr. 2019.

BORBA, R: O raciocínio combinatório na educação básica. In X Encontro Nacional de Educação Matemática, 2010, Salvador. Anais... Salvador: X ENEM, 2010.

BORBA, R.; ROCHA, C. A.; LIMA, A. P. B (2016). Conhecimentos docentes sobre combinatória: reflexões para a prática em sala de aula. In LAURINO, D. P.;

RODRIGUES, S. C. (Org) Estudos em Educação em Ciência. Editora da FURG: Rio Grande, 2016. p. 234-252. Disponível em: <

http://repositorio.furg.br/handle/1/5939>. Acesso em: 11 dez. 2019.

BORBA, R. E. de S. R.; PESSOA, C. A. dos S.; ROCHA, Cristiane de A. Como estudantes e professores de anos iniciais pensam sobre problemas combinatórios 
How Primary School students and teachers think about combinatorial problems. Educação Matemática Pesquisa: Revista do Programa de Estudos Pós-Graduados em Educação Matemática, v. 15, n. 4, p. 895-908, 2013.

MORGADO, A.C.; CARVALHO, J.B.P.; CARVALHO, P.C.P.; FERNANDEZ, P. Análise Combinatória e Probabilidade: com as soluções dos exercícios. 9 ed. Editora SBM: Rio de Janeiro, 2006.

ROCHA, C. Formação Docente e o Ensino de problemas combinatórios: diferentes conhecimentos, diversos olhares. 2011. 192 f. Dissertação (Mestrado em Educação Matemática e Tecnológica) - Universidade Federal de Pernambuco, Recife.

SANTOS, R. H. dos. Uma Abordagem do Ensino da Análise Combinatória sob a Ótica da resolução de Problemas. 2011. 232f. Dissertação (Mestrado em Educação Matemática) - Universidade Cruzeiro do Sul, UCS-SP, São Paulo.

PESSOA, C.; BORBA, R. Quem Dança com quem: o desenvolvimento do raciocínio combinatório de crianças de $1^{\mathrm{a}}$ a $4^{\mathrm{a}}$ série. ZETETIKÉ, Campinas, v.17, n.31, p. 105155, jan/jun, 2009.

PESSOA, C.; BORBA, R. O Desenvolvimento do Raciocínio Combinatório na Escolarização Básica. Em Teia: Revista de Educação Matemática e Tecnológica Iberoamericana, v.1, n.1, 2010. Disponível em:

$<$ http://emteia.gente.eti.br/index.php/emteia/article/view/4> Accessado em: 21 set. 2010.

Recebido em dezembro de 2019.

Aprovado em março de 2020. 